\title{
Congenital Urinary System Abnormality
}

National Cancer Institute

\section{Source}

National Cancer Institute. Congenital Urinary System Abnormality. NCI Thesaurus. Code C98885.

An abnormality of the kidney, ureter, bladder, or urethra that is present at birth.

Representative examples include renal hypoplasia, renal ag enesis, accessory kidney,

absence of ureter, atresia of bladder neck, and atresia of urethra. 